\title{
Assessment of knowledge, attitude and practice towards disposal of unused and expired pharmaceuticals among community in Harar city, Eastern Ethiopia
}

Yohanes Ayele* and Mulu Mamu

\begin{abstract}
Background: Pharmaceuticals are produced and consumed in increasing volume every year. Unfortunately, not all medications that go in to the hand of the consumers get consumed; large quantities remain unused or expire. The accumulation of medication at household and unsafe disposal of unwanted medicines could lead to inappropriate medicine sharing, accidental childhood poisonings and diversion of medicines to illicit use.

Methods: A descriptive cross-sectional study was conducted among 695 residents in kebele(ward) 16 of Jinela woreda(district), Harar city from February 27-April 27. A multi-stage sampling technique was used to select individual households. Face-to-face interview using structured questionnaires were conducted to collect data from each study subject. The cleaned data was entered in to epidata analyzed using SPSS version 20 software.

Descriptive statistics on sample characteristics was computed including frequencies and percentage and presented using tables and figures.

Results: Most participants displayed correct understanding toward medication waste (72.9\%) and its effect on environmental if disposed improperly (86\%). A large portion of the respondents did not know about drug-take-back system 464 (66.9\%). In order to minimize the entry of pharmaceuticals into environment, $68.6 \%$ of the participants suggested the need for proper guidance to the consumer. Majority of the respondents believed risk related to the presence of unwanted drug in home, potential harm to children, lack of adequate information on safe disposal practice and need for take-back program. Approximately $66 \%$ of the respondents had unused medicine stored at home and the common types of medicines kept in households were analgesics (62.7\%) and antibiotics (24\%). Preferred ways of disposal of both unused and expired medicine was throwing away in household garbage (53.2\%) and two third of them disposed the pharmaceuticals in its original package and dosage form.

Conclusion: In present study, there was high practice of keeping medication at home and most disposal approach indicated by the participants was not recommended methods. Awareness about proper disposal of unused and expired medicines among the public should be created. Guidelines on safe disposal are required and an organized method of collecting unused and expired pharmaceuticals needs to be introduced.
\end{abstract}

Keywords: Pharmaceuticals, Disposal practices, Unused, Expired, Knowledge, Attitude

\footnotetext{
* Correspondence: yohanesayele@ymail.com

Department of Clinical Pharmacy, School of Pharmacy, College of Health and

Medical Sciences, Haramaya University, P.O. Box 235, Harar, Ethiopia
}

(c) The Author(s). 2018 Open Access This article is distributed under the terms of the Creative Commons Attribution 4.0 International License (http://creativecommons.org/licenses/by/4.0/), which permits unrestricted use, distribution, and

reproduction in any medium, provided you give appropriate credit to the original author(s) and the source, provide a link to the Creative Commons license, and indicate if changes were made. The Creative Commons Public Domain Dedication waiver (http://creativecommons.org/publicdomain/zero/1.0/) applies to the data made available in this article, unless otherwise stated. 


\section{Background}

A large volume of pharmaceuticals and health care products are used annually for diagnosis, treatment or prevention of health conditions. However, not all products that go in to the hand of consumers get consumed; large quantities go unused or expire. Medications may accumulate in households for a variety of reasons: improvement of the patient's medical condition, oversized medication packages, death of the patient and change in prescription due to side effects or lack of therapeutic effect, poor adherence as the result of patients doubting the need for medication, fear of adverse effects or forgetfulness also contribute to the medication wastage $[1,2]$ Improper disposal of medications pose a significant environmental risk such as on the water system. A long term environmental exposure to pharmaceuticals could lead to hazardous effect especially on vulnerable populations, including pregnant women, newborn, and children [3]. In addition, evidence shows that the presence of antibiotics in environment may lead to antibiotic resistance [4]. Furthermore, storage of unwanted or unused medication in the household provides an opportunity for misuse and abuse when one inadvertently takes them [5]. Subsequently, the disposal practice of unused medicines has become a worldwide challenge catching the attention of policy makers, health professionals, pharmaceuticals companies and the community in general.

Study conducted in different areas indicated not only diverse practice of disposal of unused medicine but also respondents were not fully aware of appropriate approaches. For example, study conducted in Kenya [6] and Nigeria [7] revealed that the most preferred disposal method for unused pharmaceuticals was throwing in garbage bins followed by flushing in the toilets. In other study, the respondents kept the drug in their home because they were not sure what to do with them and some other shared to friends and families $[8,9]$. These studies clearly show that most of the respondents lack of awareness in proper methods of dispose of unwanted medicines.

Globally, safe disposal of expired, unwanted, or unused medications particular by the consumers is of high concern. Many developed countries have programs aimed at disposal of unused medicines. For instance, in Australia and Canada's there has been the National Return and Disposal of Unwanted Medicines Project which is fully supported by the government and pharmaceutical industry [10]. The drug take-back programs are also common in the United Kingdom and Sweden [11].

Unfortunately in African countries, programs or system advocating safe disposal practices of unused medicines are still limited. In Ethiopia, there are no national policies that are aimed to control safe disposal of unused medicines and create public awareness on the issue. To encourage safe and appropriate disposal of pharmaceutical by community as well as bring the issue to the concern of the government, understanding the level of knowledge and attitude of community toward disposal of unused pharmaceuticals would be important step. Moreover, information on commonly employed method of disposal of unused pharmaceuticals would help the process of awareness creation on proper ways of removal of unused medicines. Therefore, this study was conducted to assess the knowledge, attitude and practices toward disposal of unused and expired pharmaceuticals among households in Harar city, Eastern Ethiopia.

\section{Methods}

\section{Study design and description of study settings}

The descriptive cross-sectional study design was conducted in Harar city, Eastern Ethiopia from February 27-April 27, 2018. Harar is located $526 \mathrm{~km}$ from Addis Ababa, the capital of Ethiopia. The region, Harar, is structured with 9 woredas(districts) that comprises 36 kebeles(wards). Harar city is composed of 6 woredas and 19 kebeles.

\section{Study design}

The study was conducted through face-to-face interview using structured questionnaires to assess the knowledge, attitude andpractices towards disposal of unused and expired pharmaceuticals among community in Harar city, Eastern Ethiopia.

\section{Population}

The source population was all households of Harar City and one resident from each house in selected study kebeland available during study period was included in this study. Residents who are less than 18 years old and unable to give interview were excluded from the study.

\section{Sample size determination and sampling technique}

The sample size was determined using the single proportion formula and assuming $p$ value of 50\%, margin of error $5 \%$, confidence interval of $95 \%$. By considering design effect and non-respondents a total of 695 sample size was used in the study. A multi-stage sampling technique was used to select households. Jinela woredawas selected from all woredas of Harar city by using a simple random sampling technique. Kebele 16 was selected from all kebeles of Jinela woreda by using similar approach (Fig. 1). The study unit, households in kebele 16, was selected using a systematic sampling technique.

\section{Data collection procedure}

Data was collected through interviews using structured questionnaires adapted from previous studies $[8,9]$ and modified to suit our purpose. Both close and open ended 


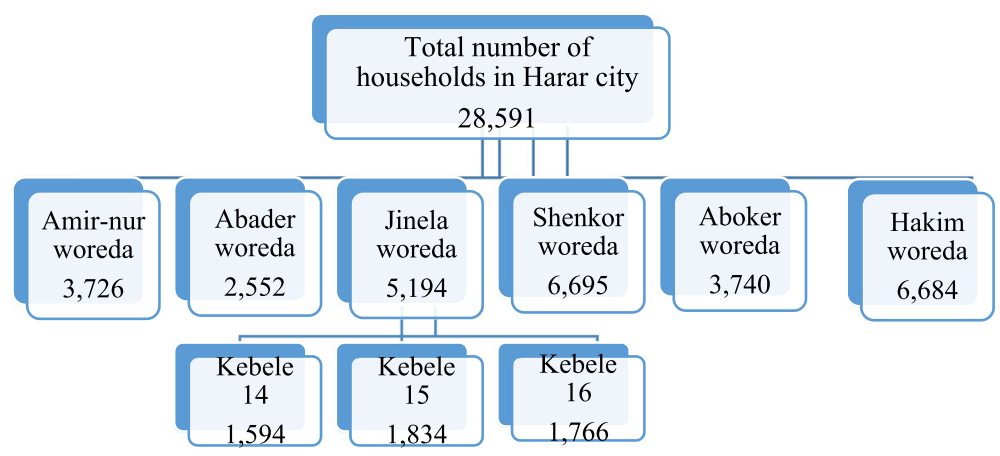

Fig. 1 The schematic presentation of a multi-stage sampling technique used to select representative study kebel in Harar city, 2018

questionnaires were prepared in English language including all relevant variables based on the objectives of study. The tools used have four section designed to address; sociodemographic characteristics, knowledge, attitude and practice of participants toward unused and expired medications disposal. The final English version of questionnarieswere translated to Amharic and Oromiffa language by expert user of respective language. The translation was made by considering the conceptual equivalence of each questions and typical respondents. The questionnaires were translated back to English by independent translators to check consistence. Furthermore, pretest was conducted on the study population and important modifications were made accordingly.. Finally, the data was collected by two individuals, graduating pharmacy students.By training it was assured that the interview was effective and collector got the theme clearly..

\section{Data processing and analysis}

The cleaned data was entered in to epidata and analyzed using SPSS version 20 software. Descriptive statistics on sample characteristics was computed including frequencies and percentage and presented using tables and figures.

\section{Results}

Socio-demographic characteristics of the participants

Almost all (694) approached individuals agreed to participate in the study giving $99.8 \%$ response rate. Among the total respondents, 368 (53.0\%) were men and 326 (47.0\%) were women. The majority were married 362 (52.2\%) and most of the respondents had a monthly income of less than 6900 Ethiopian birr (250 USD) (Table 1).

\section{Participants knowledge of unused and expired pharmaceuticals disposal}

As presented in Table 2, the majority of the respondents 506 (72.9\%) knew about medication waste. On the other hand, a large portion of the respondents did not know about drug-take-back system 464 (66.9\%). A large share of the respondents (86\%) correctly responded that improper disposal of unused and expired medicine could have detrimental effects on the environment. In order to minimize the entry of pharmaceuticals into environment, $68.6 \%$ of the participants suggested the need for proper guidance to the consumer. In response to a question about how to create the awareness among community, $49.57 \%$ answered that the best source is electronic media, $24.50 \%$ respondents mentioned Physicians. Surprisingly, only $8.5 \%$ of the participants held pharmacist responsible.

\section{Participants attitude toward unused and expired pharmaceuticals disposal}

Just more than half of the respondents (52.4\%) "Strongly agreed" about potential risks related to that presence of unused and expired medicines at home. Further, 61.7\% of the respondents also "strongly agreed" that children are more at danger with unused and expired medicines while $38.8 \%$ of the respondents "strongly agreed" that lack of adequate information on safe disposal practices. With regards to take back programs, the respondents gave one sided opinions where $46.8 \%$ and $30.4 \%$ participant said programs should be mandatory; "strongly agreed" and "agreed" about the importance of the program respectively (Table 3 ).

\section{Participants practice of unused and expired pharmaceuticals disposal}

Approximately, two third of the participants had unused medicine at their home during the study period. The most preferred disposal practice for unused and expired pharmaceuticals was throwing in household garbage (53.2\%). Interestingly, only $1 \%$ of the respondents perceived that returning unused medicines to the pharmacies would be the appropriate disposal practice. Around two third of respondents discarded the expired medications in its original package and dosage form, $15.4 \%$ did 
Table 1 Socio-demographic characteristics of participants in Harar City, Eastern Ethiopia from February 27-April 27, 2018 $(n=694)$

\begin{tabular}{|c|c|}
\hline Variable & Frequency (\%) \\
\hline \multicolumn{2}{|l|}{ Age (years) } \\
\hline $18-24$ & $193(27.8)$ \\
\hline $25-35$ & $214(30.8)$ \\
\hline 35 and above & $287(41.4)$ \\
\hline \multicolumn{2}{|l|}{ Gender } \\
\hline Male & $368(53.0)$ \\
\hline Female & $326(47.0)$ \\
\hline \multicolumn{2}{|l|}{ Religion } \\
\hline Orthodox & $440(63.4)$ \\
\hline Muslim & $146(21.0)$ \\
\hline Protestant & $99(14.3)$ \\
\hline Others $^{b}$ & $9(1.3)$ \\
\hline \multicolumn{2}{|l|}{ Educational } \\
\hline Illiterate & $50(7.2)$ \\
\hline Primary (1-8) & $114(16.4)$ \\
\hline Secondary (9-12) & $275(39.6)$ \\
\hline College and above & $255(36.7)$ \\
\hline \multicolumn{2}{|l|}{ Marital status } \\
\hline Single & $272(39.2)$ \\
\hline Married & $362(52.2)$ \\
\hline Divorced & $35(5.0)$ \\
\hline Widowed & $25(3.6)$ \\
\hline \multicolumn{2}{|l|}{ Occupations } \\
\hline Self employed & $362(52.2)$ \\
\hline Governmental employee & $137(19.7)$ \\
\hline Student & $91(13.1)$ \\
\hline Housewife & $81(11.7)$ \\
\hline Others $^{c}$ & $18(2.6)$ \\
\hline \multicolumn{2}{|l|}{ Monthly income $(\mathrm{ETB})^{\mathrm{a}}$} \\
\hline$<1380$ & $222(32)$ \\
\hline $1381-6900$ & $431(62.1)$ \\
\hline $6901-13,800$ & $41(5.9)$ \\
\hline
\end{tabular}

${ }^{a}$ Classification is according to WHO income level scale for developing countries; ETB: Ethiopian birr; ${ }^{\mathrm{b} C a t h o l i c}$, Jehovah Witness and Traditional. 'daily labors, retired, no job

not know about the practice of expired medication disposal, 12.2\% crushed before disposal (Table 4).

\section{Respondents practice on unused and expired medication disposal}

Reasons for possessing unused medication were mostly due to a resolved/improved disease or symptoms (53.31\%) and forgetting to take (16.71\%) (Fig. 2).'
Table 2 Participants knowledge of unused and expired Pharmaceuticals disposal in Harar City, Eastern Ethiopia from February 27-April 27, $2018(n=694)$

\begin{tabular}{ll}
\hline Questions/statements & $n(\%)$ \\
\hline Do you know about medication waste? & $506(72.9)$ \\
Yes & $188(27.1)$ \\
No & \\
Do you ever read medicines disposal instructions? & $327(47.1)$ \\
Yes & $367(52.9)$ \\
No & \\
Do you know about "drug-take-back system"? & $230(33.1)$ \\
Yes & $464(66.9)$ \\
No &
\end{tabular}

Do you know that misused/repeated change or failing to complete antibiotics may cause drug resistance?

Yes

$542(78.1)$

No

$152(21.9)$

Improper disposal of unused and expired

medicines can affect the environment and health.

Yes

$597(86.0)$

No

$97(14.0)$

How could be hazardous effect of unused and expired medicines minimized or controlled?

Providing proper guidance to the consumer

$476(68.6)$

Prescribing in quantities and for duration that ensure patient compliance

$32(4.6)$

by doctor

Donating or sharing the unused medicines 34 (4.9)

Other $^{\mathrm{a}}$

Stakeholder for creating the awareness among community about proper disposal of unused and expired medicines

\begin{tabular}{ll} 
Electronic Media & $344(49.6)$ \\
Physician & $170(24.5)$ \\
Pharmacy & $59(8.5)$ \\
Newspaper & $35(5.0)$ \\
All sources & $78(11.2)$ \\
Other $^{b}$ & $8(1.2)$ \\
\hline
\end{tabular}

${ }^{a}$ keeping in safe place, disposing in toilet, burning ${ }^{b}$ health bureau, environmental agency, drug regulatory agency

The most common types of pharmaceuticals kept in households were analgesics (62.7\%) followed by antibiotics (24\%) (Fig. 3).

\section{Discussion}

The aim of this study was to assess the knowledge, attitudes and disposal practices of unused and expired pharmaceuticals among households in Harar city. Most 
Table 3 Perceptions on unused and expired Pharmaceuticals among Households in Harar City, Eastern Ethiopia from February 27April 27, $2018(n=694)$

\begin{tabular}{|c|c|c|c|c|c|}
\hline Statement & $\begin{array}{l}\text { Strongly disagree } \\
n(\%)\end{array}$ & $\begin{array}{l}\text { Disagree } \\
n(\%)\end{array}$ & $\begin{array}{l}\text { Neutral } \\
n(\%)\end{array}$ & $\begin{array}{l}\text { Agree } \\
n(\%)\end{array}$ & $\begin{array}{l}\text { Strongly agree } \\
n(\%)\end{array}$ \\
\hline Unused and expired medicines present potential risks at home & $33(4.8)$ & $30(4.3)$ & $7(1.0)$ & $260(37.5)$ & $364(52.4)$ \\
\hline $\begin{array}{l}\text { Children are more vulnerable to the risks of associated with } \\
\text { unused and expired household medicines }\end{array}$ & $22(3.2)$ & $17(2.4)$ & $6(0.9)$ & $221(31.8)$ & $428(61.7)$ \\
\hline $\begin{array}{l}\text { There is lack of adequate information on safe disposal of } \\
\text { unused and expired household medicines }\end{array}$ & $44(6.3)$ & $43(6.2)$ & $26(3.7)$ & $312(45.0)$ & $269(38.8)$ \\
\hline $\begin{array}{l}\text { Doctors and healthcare professionals do provide advice on } \\
\text { safe disposal of unused and expired household medicines }\end{array}$ & $122(17.6)$ & $167(24.1)$ & $59(8.5)$ & $239(34.4)$ & $107(15.4)$ \\
\hline $\begin{array}{l}\text { Take-back programs of unused and expired medicines } \\
\text { should be mandatory }\end{array}$ & $41(5.9)$ & $63(9.1)$ & $54(7.8)$ & $211(30.4)$ & $325(46.8)$ \\
\hline
\end{tabular}

Table 4 Disposal practice of unused and expired pharmaceuticals among households in Harar City, Eastern Ethiopia from February 27-April 27, $2018(n=694)$

\begin{tabular}{ll}
\hline Questions & $n(\%)$ \\
\hline Did any quantity of purchased medicine remain unused at your home? \\
Yes & $459(66.2)$ \\
No & $235(33.8)$ \\
What do you do with the unused medicines? & \\
Throw away in household garbage & $369(53.2)$ \\
Flush unused medications in toilet/sink & $166(23.9)$ \\
Keep at home until expired & $111(16.0)$ \\
Burn & $15(2.2)$ \\
Donate to hospital & $13(1.9)$ \\
Give to friends or relatives & $13(1.9)$ \\
Return back to pharmacy & $7(1.0)$ \\
What do you do with the expired medicines? & \\
Throw away in household garbage & $369(53.2)$ \\
Flush expired medications in toilet/sink & $258(37.2)$ \\
Return back to pharmacy & $15(2.2)$ \\
Give to friends or relatives & $3(0.4)$ \\
I don't know what to do & $27(3.9)$ \\
Other ${ }^{a}$ & $22(3.2)$ \\
Do you separate unused medicines before disposal? & \\
Yes & $446(64.3)$ \\
No & $248(35.7)$ \\
Cras of discarding expired medicines & $41(12.2)$ \\
Diluted with water & $461(66.4)$ \\
\hline & $107(15.4)$ \\
\hline
\end{tabular}

participants displayed correct understanding toward medication waste and its effect on environmental disposed improperly. However, most respondents were not aware of drug-take back system and had various opinions in ways of controlling or minimizing the effect of unused medicine. Majority of the respondents agreed in lack of adequate information on safe disposal practice. A large portion of participants kept drug at their home during the study period. Analgesics were the most common drugs found at home. Preferred ways of disposal of both unused and expired medicine was throwing away in household garbage as it is.

In this study, a large share of the respondents correctly understood detrimental effects of improper disposal of unused and expired medicine on the environment. This finding is higher than a study conducted in Karachi City [12] and Serbia [13]. However, it is significantly lower than study conducted in Kabul where almost entire sample felt that improper disposal of unused and expired medicines can affect the environment and health [9]. This might be due to lack of awareness creation programs and lack of effort from responsible governmental bodies to create awareness about the negative impacts of improper disposal of unused and expired medicines.

In this study, a large portion of the respondents did not know about drug-take-back-system. Although this

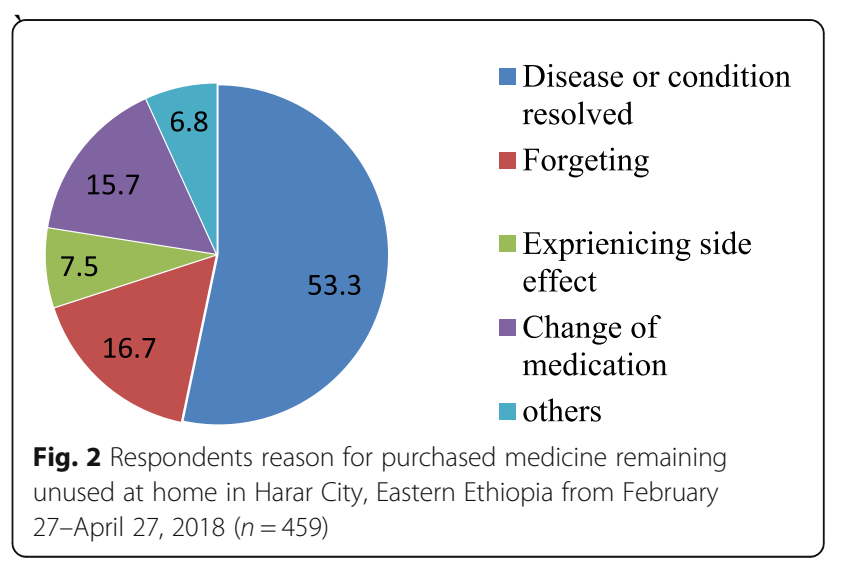




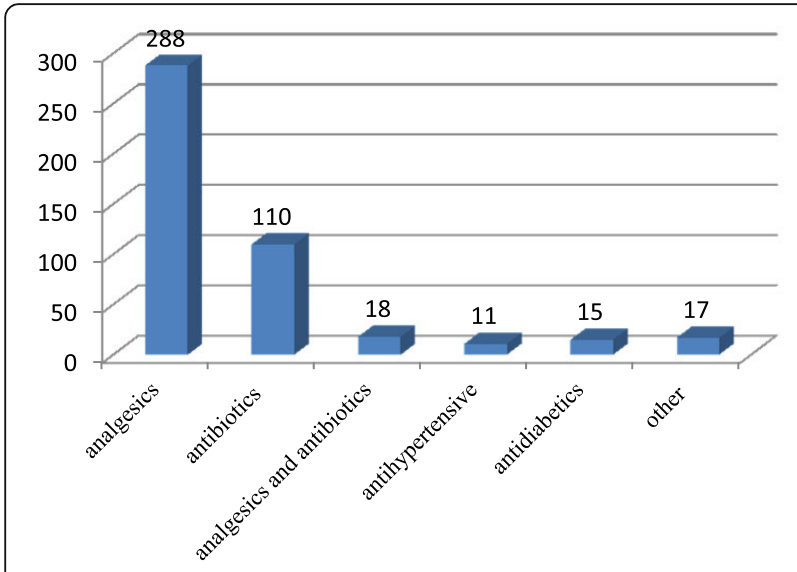

Fig. 3 Type of pharmaceuticals remained unused at home among households in Harar City, Eastern Ethiopia from February 27-April 27, $2018(n=459)$

result is much encouraging compared to study done elsewhere $[14,15]$, it shows lack of understanding about one the effective method of disposal of unused and expired medicine. This might be due to lack of an already established drug-take-back-system in Ethiopia, particularly in Harar city.

In present study, about two third of participants suggested need for proper guidance on disposal of unused and expired medicine while minor portion of the participants suggested prescribing less quantity. This result is inconsistent with a study conducted in Karachi City [12]. This finding indicates poor involvement of health care professional in creating awareness and guiding the consumers on proper disposal practice.

In our study, majority of the respondents agreed on lack of adequate information on safe disposal practice. Around half of participants denied receiving any information on safe disposal of unused and expired medicine from physicians and other health care professional. This finding is consistent with studies done elsewhere $[16,17]$. This report implies need for public education to improve consumers' awareness through various ways by responsible bodies including health care professionals, mass media, environmental agency.

In current study about two third of the respondents had leftover, unused or unwanted medications which is comparable with a study conducted in Gujarat [17] but slightly higher than study conducted among Serbian households (44.4\%) [13]. This result, however, is significantly lower than study conducted in Kuwait [18] and Kabul [9]. This difference might be due to different systems and educational programs available in different countries. This increased storage of unused or expired medication in the household should be given emphasis as it can lead to irrational drug use since most people keep unused medications at home for future use or to share to friends/family members. It can also leads to accidental childhood poisonings.

In this study, the common types of medications kept in households were analgesics followed by antibiotics. This report is much higher than studies done elsewhere Nigerian [7], India [17] and USA [19] where the share of aforementioned category of the drugs had less share. This difference may be due to high prevalence of self-medication practice in Harar city. The increased presence of antimicrobials at home of should get serious consideration since it may add up to the problem of antimicrobial resistance.

In current study, the frequently stated reason for having leftover or unwanted medications was improvement in medical condition or resolved medical condition. This finding is similar to the finding from New Zealand [20] and Ghana [8]. However, it is different from study conducted in Kuwait where change or discontinuation of medication by the doctors' was the main reason for having unused medicine at home $[8,18]$. This report is worrying since the stated reason might be due to non-adherence.

In present study, the most preferred disposal practice for both unused and expired medicine was throwing in household garbage followed by flushing in toilet. This finding is consistent with study done elsewhere $[6,8,20$, 21]. In this study, very few people considered returning to pharmacy or health professionals as appropriate way of disposing unused or expired medicine. This might be due to lack of awareness about proper disposal of medications. This reasoning become more evident when we compare those findings with study conducted in Sweden where just under half of participants returned unwanted medication back to pharmacy [11]. The difference seen might be due to existence of system that encourage proper disposal of unused medicine in later country.

Around two third of respondents in the current study discarded or was willing to discard the expired pharmaceuticals in its original package and dosage form. Similar finding was reported elsewhere $[8,12]$. This approach is contradicting with recommended ways of discarding expired medicine. For example, FDA [22] recommends crushing or dissolving in water and deletion of all personal information from medicine packaging. This approach is very important since it can prevent the drug re-utilization by scavengers.

\section{Limitation}

This study should be interpreted cautiously for many reasons. Its generalizability is questionable since the study was conducted only in one center. In addition, since this is descriptive cross sectional design we were not able to identify associated factors with knowledge, attitude and practice of the participants. 


\section{Conclusion}

In present study, there was high practice of keeping unused medication at home.although majority of the them are aware of potential risk associated to the presence it. There was lack of adequate information on safe disposal practice and most respondent mentioned the need for system that encourage safe disposal of unwanted pharmaceuticals such as "drug take-back program". In this study, most preferred methods for disposal of unused and expired medicines most were not recommended method.

\section{Abbreviations \\ FDA: Food and Drug administration; SPSS: Statistical Package for Social Sciences; USA: United State of America}

\section{Acknowledgements}

We extend our heartfelt thanks to all directly and indirectly involved in this study and particularly to the participants. Our appreciation also goes to the data collectors who showed the utmost effort in acquiring appropriate information.

\section{Availability of data and materials}

The data collection tools are attached as an additional supporting file. The datasets are available from the corresponding author on reasonable request.

\section{Authors' contributions}

Both authors actively participated during the conception of the research idea, development of a research protocol, data collection, analysis and interpretation. MM supervised the data collection and analysis process. YA interpreted the finding and authored the manuscript. Both authors have read and agreed to the final manuscript.

\section{Ethics approval and consent to participate}

Ethical clearance was obtained from Haramaya University, Institutional Health Research Ethics Review Committee. Formal letter was submitted to all concerned bodies in the study area to get their co-operation in facilitating the study. Verbal informed consent was obtained from the study participants after the significance of the study made clear and permission for face-to-face interviews was asked politely. Every effort was made to inform participants in a manner that would encourage free choice of participation without any physical or psychological influence. Interviews were done with the respect of the culture, norms and religions of the study population. All personal data was secured and concealed during data entering and analysis process.

\section{Consent for publication}

Not applicable since there is no individual details in our result.

\section{Competing interests}

The authors declare that they have no competing interests.

\section{Publisher's Note}

Springer Nature remains neutral with regard to jurisdictional claims in published maps and institutional affiliations.

Received: 13 August 2018 Accepted: 4 October 2018

Published online: 15 November 2018

\section{References}

1. Bound JP, Voulvoulis N. Household disposal of pharmaceuticals as a pathway for aquatic contamination in the United Kingdom. Environ Health Perspect. 2005;113(12):1705-11.

2. Vogler S, Leopold C, Zuidberg C, Habl C. Medicines discarded in household garbage: analysis of a pharmaceutical waste sample in Vienna. J Pharm Policy Prac. 2014;7:6.

3. Daughton CG. Cradle-to-cradle stewardship of drugs for minimizing their environmental disposition while promoting human health. II. Drug disposal, waste reduction, and future directions. Environ Health Perspect. 2003;111(5): 775-85.
4. Costanzo SD, Murby J, Bates J. Ecosystem response to antibiotics entering the aquatic environment. Mar Pollut Bull. 2005;51(1-4):218-23.

5. Beirens TM, van Beeck EF, Dekker R, Brug J, Raat H. Unsafe storage of poisons in homes with toddlers. Accid Anal Prev. 2006;38(4):772-6.

6. Angi'enda SA, Bukachi SA. Household knowledge and perceptions on disposal practices of unused medicines in Kenya. J Anthropol Archaeol. 2016;4(2):1-20.

7. Auta A, Omale S, Shalkur D, Abiodun AH. Unused medicines in Nigerian households: types and disposal practices. J Pharmacol Pharmacother. 2011; 2(3):195-6.

8. Osei-Djarbeng SN, Larbi GO, Abdul-Rahman R, Osei-Asante S, Owusu-Antwi R. Household acquisition of medicines and disposal of expired and unused medicines at two suburbs (Bohyen and Kaase) in Kumasi - Ghana. Pharma Innov J. 2015;4(8):85-8.

9. Bashaar M, Thawani V, Hassali MA, Saleem F. Disposal practices of unused and expired pharmaceuticals among general public in Kabul. BMC Public Health. 2017;17(1):45.

10. Tong AY, Peake BM, Braund R. Disposal practices for unused medications around the world. Environ Int. 2011;37(1):292-8.

11. Persson M, Sabelstrom E, Gunnarsson B. Handling of unused prescription drugs--knowledge, behaviour and attitude among Swedish people. Environ Int. 2009;35(5):771-4

12. Ahsaan Ahmed, Nousheen Mushtaq, Muhammad Tariq, Maliha Durrani SA, Muhammad Arif, Yasmeen G. Disposal practices of unused and expired pharmaceuticals in Karachi and their impact on health and environment. JUMDC 2013;4(2).

13. Paut Kusturica M, Tomas A, Tomic Z, Bukumiric D, Corac A, Horvat O, et al. Analysis of expired medications in Serbian households. Slov J Public Health. 2016;55(3):195-201.

14. Zubair Khalid labu, Mir Md Abdullah Al-Mamun, Md. Harun-or-Rashid, Sikder K. Knowledge, Awareness and disposal practice for unused medications among the students of the Private University of Bangldesh. J Biomed Pharm Res 2015;2(2):26-33.

15. Azad AK, Ansary RH, Akhter A, Mostofa Al-Mamun SM, Uddin M, Rahman MM. Disposal practice for unused medications among the students of the International Islamic University Malaysia. J Appl Pharm Sci. 2012;02(07):101-6.

16. AlAzmi A, AlHamdan H, Abualezz R, Bahadig F, Abonofal N, Osman M. Patients' knowledge and attitude toward the disposal of medications. J Pharm 2017;2017:8516741.

17. Sonowal S, Desai C, Kapadia JD, Desai MK. A survey of knowledge, attitude, and practice of consumers at a tertiary care hospital regarding the disposal of unused medicines. J Basic Clin Pharm. 2016;8(1):4-7.

18. Abahussain EA, Ball DE, Matowe WC. Practice and opinion towards disposal of unused medication in Kuwait. Med Princ Pract. 2006;15(5):352-7.

19. Law AV, Sakharkar P, Zargarzadeh A, Tai BWB, Hess K, Hata M, et al. Taking stock of medication wastage: unused medications in US households. Res Soc Adm Pharm. 2015;11(4):571-8.

20. Braund R, Peake BM, Shieffelbien L. Disposal practices for unused medications in New Zealand. Environ Int. 2009;35(6):952-5.

21. Al-Shareef F, El-Asrar SA, Al-Bakr L, Al-Amro M, Alqahtani F, Aleanizy F, et al. Investigating the disposal of expired and unused medication in Riyadh, Saudi Arabia: a cross-sectional study. Int J Clin Pharm. 2016;38(4):822-8.

22. United States Food and Drug administration. How to dispose unused medications, 2011. Cited[15 July 2018]. Available from: www.fda.gov/ forconsumers/consumerupdates/ucm101653

\section{Ready to submit your research? Choose BMC and benefit from:}

- fast, convenient online submission

- thorough peer review by experienced researchers in your field

- rapid publication on acceptance

- support for research data, including large and complex data types

- gold Open Access which fosters wider collaboration and increased citations

- maximum visibility for your research: over $100 \mathrm{M}$ website views per year

At BMC, research is always in progress.

Learn more biomedcentral.com/submission 